\title{
O EXERCÍCIO DO ESTUDAR NOS CURSINHOS DESTINADOS AOS CONCURSOS PÚBLICOS
}

\author{
Leonardo Del Puppo Luz \\ Camila Mariani Silva $\star \star$
}

\begin{abstract}
RESUMo
$O$ artigo discute o processo de produção da subjetividade contemporânea elaborado sobre o Estudar em alunos de cursinhos destinados aos concursos públicos. Procura-se discutir as tecnologias de poder, sobretudo na relação saberpoder, engendradas nestes "ambientes educacionais", já que tais construções sobre o Estudar produzem e perpetuam a manifestação de conceitos absolutos e verdadeiros de se pensar o estudo por meio de técnicas e procedimentos de funcionamentos ideais e idealizados. Busca-se problematizar este modelo homogêneo baseado no tecnicismo do estudar e nas falas sobre o verdadeiro visando colocar em análise o estereótipo do "fracasso" atrelado aos alunos vinculados a estes locais.

Palavras-chave: Estudar. Produção de Subjetividade. Poder-Saber. Concursos Públicos.

\section{STUdY PRACTICE IN COURSES FOR SELECTION FOR PUBLIC EMPLOYMENT}

\begin{abstract}
This article discusses the contemporary process of production of subjectivity upon the methodic way of students studying in specialized courses for selection processes for public employment. It discusses the technologies of power, especially on the knowledge-power relation, engendered in these "educational environments", inasmuch as these considerations about the studying act perpetuate the manifestation of absolute concepts of thinking the studying act as ideal and idealized techniques and actions. The article brings into discussion this homogeneous model based on studying techniques and on discourses about the truth putting in analysis the "failure" stereotype tied to the students from those "educational environments".
\end{abstract}

Keywords: Study. Production of Subjectivity. Power-knowledge. Selection processes of public employments.

\footnotetext{
* Psicólogo graduado pela Universidade Federal do Espírito Santo, pós-graduado no curso de Transdisciplinaridade e Clínica, mestrando do Programa de Pós-Graduação em Psicologia Institucional da UFES e Servidor de carreira do Ministério Público do Trabalho.

E-mail: estudaja@estudaja.com; leoluz28@hotmail.com.

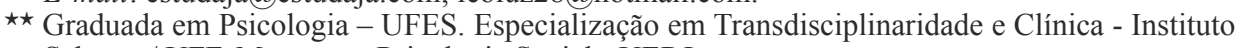
Saberes / UFF. Mestre em Psicologia Social - UERJ.
} 


\section{INTRODUÇÃO}

Percebe-se nas configurações sociais contemporâneas uma nova produção subjetiva nas relações de trabalho, com destaque significante no vetor empregabilidade e seus desdobramentos. A ação do Capitalismo Mundial Integrado ${ }^{1}$ (CMI) visa, a partir de mecanismos de funcionamentos próprios de se pensar a questão da empregabilidade, aperfeiçoar e otimizar a utilização da mão-de-obra para assim extorquir/extrair do trabalhador uma maior produtividade (corpos dóceis) em um menor espaço de tempo e com o menor custo possível - salários, tributação, propriedades, entre outros.

[...] no capital, Marx mostra o encontro de dois elementos "principais" de um lado o trabalhador desterritorializado, transformado em trabalhador livre e nu, tendo para vender a sua força de trabalho; o outro, o dinheiro decodificado, transformado em capital e capaz de a comprar [sic]. Estes dois fluxos, de produtores de dinheiro, implicam vários processos de decodificação e de desterritorialização com origens muito diferentes. Para o trabalhador livre: desterritorialização do solo por privatizações; decodificação dos instrumentos de produção por apropriação; privação dos meios de consumo por dissolução da família e da corporação; por fim decodificação do trabalhador em proveito do próprio trabalho ou da máquina. Para o capital: desterritorialização da riqueza por abstração monetária; decodificação para os Estados pelo capital financeiro e pelas dívidas públicas; decodificação do meio de produção pela formação do capital industrial (DELEUZE; GUATTARI apud HAESBAERT; BRUCE, 2002, p. 11).

Visualiza-se, a partir do exposto acima, que o modelo capitalista de produção se infiltra nas mais diversificadas fissuras existentes nas infindáveis formas de relações e nas suas condições de possibilidade de existir. Em virtude do aparecimento constante e frenético de novas tecnologias de poder, fomentadas por este modelo, o trabalhador, este entendido desde o grande executivo da transnacional ao faxineiro, está confrontando, dentro desta emergente relação homem x tecnologia, condutas, valores e formas capitalistas de funcionamento com a sua vida e suas implicações. Desta forma, o Capital, por meio de suas políticas para administrar a vida em todas as suas dimensões, produz desterritorialização ${ }^{2}$ dos seus próprios modos de vida, fato que pode ser verificado no vetor indivíduo/emprego. É significante dizermos que Deleuze e Guattari "dão importância aos processos de desterritorialização, pois é assim que eles entendem a criação do Estado e a dinâmica do capitalismo" (HAESBARTE; GLÁUCIO, 2002, p. 03). Nas palavras de Guattari (GUATTARI; ROLNIK, 1986, p. 323):

O território pode se desterritorializar, isto é, engajar-se em linhas de fuga ou até mesmo sair do seu curso e destruir-se. A espécie humana está mergulhada num imenso movimento 
de desterritorialização, no sentido de que seus territórios "originais" se desfazem ininterruptamente com a divisão social, com a ação de deuses universais que ultrapassam os quadros da tribo e da etnia, com os sistemas maquínicos que a levam a atravessar cada vez mais rapidamente as estratificações materiais e mentais.

Em outras palavras, vivencia-se no cotidiano a produção de novos processos de subjetivação na relação trabalhador/trabalho. Tais processos engendram operações de desterritorialização, as quais se desdobram em novas linhas de fuga, ${ }^{3}$ mas que são, concomitantemente, reterritorializadas pelo capital por meio de uma pluralidade e plasticidade de captura e re-inserção nos modos de produção.

\section{Cursinhos: novas ConfiguraÇões do Contemporâneo}

Um exemplo desta nova configuração ou reterritorialização da relação empregado/emprego é constatado empiricamente por meio da proliferação acentuada e maciça de Cursos - "cursinhos"4 - voltados para aprovação em concursos públicos, os quais têm objetivo final, quase exclusivo, de promoverem a admissão de pessoas em cargos nas esferas do Executivo, do Legislativo e, preferencialmente, do Judiciário.

A proliferação desses “ambientes educacionais" pode ser entendida como um novo formato na percepção deste relacionamento empregado/emprego, dado que os caminhos exploratórios engendrados pelo CMI estão chegando a certo patamar de insuportabilidade para os sujeitos. O espaço/tempo destinado ao trabalho está provocando uma redefinição das paisagens sociais, sexuais, familiares, conjugais, domésticas, de justiça e educacionais, já que todas essas paisagens estão, em algum momento, sendo perpassadas pela lógica do trabalho que está se infiltrando em um nível capilar em todos os espectros de relações desenvolvidas pelos elementos humanos constitutivos da sociedade. Certa forma subjetiva de viver balizada pela ética do trabalho atualizada e seus desdobramentos está em vigência e, assim, produzindo outras formas de pensar, de agir e de sentir o mundo e, paralelamente, nutrindo o surgimento de uma verdade que "está circularmente ligada a sistemas de poder, que a produzem e apóiam, e a efeitos de poder que ela induz e que a reproduzem" (FOUCAULT, 1979, p. 14).

Então, em que momento há uma conexão destes Cursinhos dentro dessa lógica do trabalho produzida pelo CMI? Acreditamos que o fatigamento dos sujeitos provocado por essa lógica está promovendo um repensar da vida e suas conexões com o trabalho, bem como os modos de ser do trabalhador, fazendo com que algumas certezas estejam sendo repensadas e recolocadas. É neste espaço e circunstância que a inserção em um emprego público está recriando seus significados e entendimentos. Há uma nova configuração na idéia de espaço/tempo em vigência e em plena construção. $\mathrm{O}$ viver se mesclou ao trabalho e este, por sua vez, está assumindo proporções desestabilizadoras nos sujeitos contemporâneos, fato que está provocando, dentro de sua parcela de contribuição, certa intencionalidade de migração do Sistema Privado de Trabalho para o Público. Tal 
fato migratório está se desenvolvendo basicamente devido à comparação ${ }^{5}$ entre produção/remuneração/tempo de trabalho no Sistema Privado de Emprego com o Público. Nas palavras de Pelbart (2000, p. 26):

O capitalismo atual invadiu as esferas mais privadas e íntimas da vida humana, desde a fé até o corpo biológico. Não há mais exterior para o capital [...] os últimos enclaves que ainda lhe resistiam, como o Inconsciente e a Natureza, capitularam de vez [O que dizer então sobre o trabalho, pilar fundamental e inerente ao capitalismo mundial integrado].

De maneira recíproca, tal migração para o Sistema Público fomentou e impulsionou o desenvolvimento intermediário desses espaços "educacionais". Concomitantemente a esta expansão, um esquadrinhamento intensificado por novas formas de Estudar está emergindo. Como produção de certas vinculações (expansão dos cursinhos x modos de Estudar), há a produção de uma forma-subjetiva pautada e atravessada pelos modelos homogêneos de pensar o Estudar ( $p$. ex.: totalização de horas de estudo) e os padrões pedagógico e cognitivista tradicionais, os quais são, ainda, mutuamente reforçados com o poder/saber nutridos nestes espaços intermediários.

Este artigo objetiva promover e propor um repensar sobre o Estudar, colocando em discussão suas práticas/discursos, bem como desencadear processos de desnaturalizações de determinados modelos homogêneos, coerentes e verdadeiros cristalizados sobre o exercício cotidiano de tal verbo e, assim, pensar a constituição de outros olhares. Mesclando-se a isto, busca colocar em análise tais cursinhos e seus dispositivos de funcionamento, no entanto, com certa preocupação metodológica, objetivando, assim, o não-desmembramento existencial desses locais às atuais políticas de subjetivação engendradas pelo CMI. Tal preocupação se faz necessária, já que esses cursinhos funcionam em virtude justamente destas políticas no socius. Sendo assim, não cabe realizar certo recorte anistórico destes locais, já que estes são e estão sendo produzidos em simbiose com as políticas de subjetivação fabricadas pelo CMI.

\section{Produção de Subjetividade e Cursinhos}

Falar de subjetividade é falar de uma maquínica, de um processo de produção dirigido à geração de modos de existência, ou seja, modos de agir, de sentir, de dizer o mundo. É analisar um processo de produção que tem si mesmo como produto. Precisamos entender subjetividade ao mesmo tempo como processo e produto [...] o que temos é uma subjetividade-paisagem, confundida com seu entorno, constituída nos próprios elos que compõem sua vida (TEDESCO, 2002, p. 01). 
Sendo assim, produção de Subjetividade é um processo incessante e permanente de produção social de geração, "uma processualidade e potência de produção de mundos". (TEDESCO, 2002, p. 02). Podemos dizer que Subjetividade não é algo definido previamente, já dado, revestido por uma imutabilidade ou estratificado ad infinitum. Subjetividade é um conceito multifacetado e pluralista, já que não deve ser traduzida em uma essência inicial e fundadora ou uma natureza rígida, e sim processo de produção de si o qual se fabrica com elementos heterogêneos, objetos diferenciados ou vetores de existencialização dos mais diversos (PASSOS, 2000). Partindo desta idéia, podemos afirmar que cada momento, cada circunstância da história é caracterizada por certos contornos, certos desenhos, certos percursos afetivos, sociais, familiares, religiosos, educacionais, entre outras relações, que irão produzir/fabricar/desenvolver formas de sentir, de trabalhar, de desejar, de amar, "de estudar", de promover a vida e suas infinitas formas.

Partindo deste conceito de construção das subjetividades, podemos afirmar que este "ambiente educacional" é um lugar que está ocupando um espaço de extrema importância no contexto social contemporâneo, uma área fundamental na constituição da subjetividade e produtor de uma forma-subjetiva. O Cursinho Preparatório para Concursos Públicos é perpassado e marcado pelas novas configurações no campo das transformações sociais, em especial na conexão educação e trabalho pautada pela atuação do Neoliberalismo e seus aspectos pertinentes na constituição da subjetividade, tendo como vetor central de formação subjetiva contemporânea os desdobramentos na questão da empregabilidade, questão esta que produz, dentro desses ambientes, uma forma-sujeito balizada e garantida por preceitos universais de gestão e de funcionamento da vida.

\section{Poder e Verdade}

É neste contexto que a relação de poder entre alunos e professores nestes locais de ensino está sofrendo uma reformulação nefasta, construindo uma nova forma subjetiva de se entender a educação, principalmente dentro do método tradicional no campo do ensino e da aprendizagem, o qual tem seu ideal cognitivo amplificado e reproduzido intensamente. A própria idéia de "fracasso escolar" está sendo reconfigurada e expandida para um alto grau de individualização e culpabilização. As formas de exercício deste poder-saber em andamento nestes "ambientes educacionais" estão atingindo patamares de insuportabilidade para um provável e possível aparecimento de linhas de fuga. O desenvolvimento de um amplo espectro de singularidades e de multiplicidades humanas está sendo aniquilado, certa mortificação coletiva de possíveis singularidades está em vigência e em produção constante, fato que está engendrando o achatamento de aberturas diversas e ilimitadas para se criar outras formas de se entender aprendizagem e principalmente de se entender o sentido pluralístico do verbo transitivo Estudar. As formas de criar um estudo diferenciado, potencializador, inventivo, ou até mesmo criativo, estão sendo "exterminadas". O estar aberto ao novo, ao intempestivo, pode, segundo a lógica de funcionamento nestes ambientes, ocasionar múltiplos sofrimentos. Certa lógica do adoecimento está em vigência. 
Virginia Kastrup (2005) em seu texto "Políticas Cognitivas na Formação do Professor e o Problema do Devir - Mestre” traz um importante conceito para ser pensado dentro desses "ambientes educacionais": as idéias de uma "aprendizagem inventiva" que possa confrontar alguns problemas no campo da educação contemporânea. Virgínia (2005, p. 13) afirma que:

A invenção não se confunde com criatividade [...] a invenção de que eu falo não é a capacidade de solução de problemas, mas sobretudo de invenção de problemas. Além disso, a invenção é sempre a invenção do novo, sendo dotada de uma imprevisibilidade que impede sua investigação e o tratamento no interior de um quadro de leis e princípios invariantes da cognição.

Esta invenção de problemas é entendida por meio de uma negação ou afastamento da "invariância das condições de possibilidade da cognição e reconhecer seu caráter temporal e de diferenciação interna” (KASTRUP, 2005, p. 01). É necessário dizer ainda que esta forma inventiva não é demarcada por percursos pré-estabelecidos, não é realizada por meio de protocolos ou estruturas cognitivas, as quais são imutáveis, tal como percebemos nas teorias do desenvolvimento cognitivo. Podemos afirmar que é antes de tudo uma deriva desenvolvida pelas infinitas vinculações/conexões com as forças do mundo (Kastrup, 2005).

Todavia, tal conceito esbarra profundamente em formas de exercício do poder. Este, segundo Foucault, é entendido como algo que se exerce de maneira estratificada e linear, não está localizado em lugares pré-definidos, muito menos está aprisionado no campo do individual. "O poder não é um bem, mas é algo que se exerce em rede, e nessa rede todos os indivíduos circulam, sendo que qualquer um pode estar em posição de ser submetido ao poder, mas também de exercê-lo". (PRATA, 2005). Poderíamos dizer que não se trata de apontar quem tem "o poder", mas quem o exerce e com isso quem ou o que tem o discurso do verdadeiro. Verdade e Poder se mesclam e se acoplam, produzindo sentidos e sobrecodificações. Nas palavras de Foucault (1979, p. 12):

O importante é que verdade não existe fora do poder ou sem poder. A verdade é deste mundo; ela é produzida nele graças a múltiplas coerções e nele produz efeitos regulamentados de poder. Cada sociedade tem seu regime de verdade, sua "política geral" de verdade: isto é, os tipos de discurso que ela acolhe e faz funcionar como verdadeiros; os mecanismos e as instâncias que permitem distinguir os enunciados verdadeiros dos falsos, a maneira como se sancionam uns e outros; as técnicas e os procedimentos que são valorizados para a obtenção da verdade; o estatuto daqueles que têm o encargo de dizer o que funciona como verdadeiro. 
No entanto, nestes cursinhos, diversamente de outros espaços representativos no campo do ensino-aprendizagem, como escolas (ensino fundamental e médio) e universitário, o professor é um dispositivo produtor e reprodutor de relações de poder-saber, já que coloca em funcionamento práticas, técnicas e dispositivos de poder, com destaque ao posicionamento social em que este está inserido dentro do campo das classes sociais, especialmente pelo viés do status quo. "Um instrumento que se exerce por meio de pequenas válvulas, pequenos difusores, minúsculas engrenagens, microscópicas sinapses através das quais o poder passa e se acha reconduzido por ele mesmo" (DROIT, 2006. p. 95). O professor, a partir de uma posição inabalável, onipotente, onipresente e desejável pelo corpo discente, está sendo capaz de fabricar/reproduzir subjetividades serializadas ${ }^{6}$ e docilizadas. É fundamental lembrarmos que não há qualquer tipo de intenção afirmativa e impositiva de que o Professor seja o produtor consciente e pragmático dos mecanismos de exercício do poder ${ }^{7}$, mas que, na verdade, também é parte integrante desta máquina de produção dessas subjetividades serializadas; ele é, ao mesmo tempo, produto e produtor. "O poder deve ser analisado como algo que circula, ou melhor, algo que circula em cadeia" (FOUCAULT, 1979, p. 183). O poder não tem seus espaços ou fronteiras estritamente delimitadas ou está restrito ao uso de algum sujeito, este está sempre na posição de praticá-lo ou de sofrer seus efeitos, sendo assim, os sujeitos "são o alvo inerte ou consentidor do poder, são sempre seus intermediários. Em outras palavras, o poder transita pelos indivíduos, não se aplica a eles" (FOUCAULT, 2005, p. 35).

Nestes "ambientes educacionais" a relação saber e poder apresenta determinada vinculação potencializada e, ao mesmo tempo, amplificadora na condução das ações dos sujeitos. A "verdade" e a sucessão linear de quando, quanto, onde, como e qual caminho seguir sobre a produção do estudar exerce relações de poder, ${ }^{8}$ já que possui efeitos práticos e políticos, sobretudo no que tange à condução das próprias ações dos sujeitos (ações eventuais, atuais, futuras ou presentes), isto é, tais relações de poder produzem certa especificidade que as tornam, no nosso entender, mais vigorosas e produtoras de subjetividades. Como afirmou Foucault, a posição dos intelectuais e dos sábios nos sistemas de produção, nos sistemas políticos é um fator de produção de verdade (DROIT, 2006). Com isso, o saber emanado desses intelectuais, tanto no campo teórico quanto no da experiência de vida, está efetivamente acoplado a uma série de relações de poder e seus desdobramentos sobre os corpos e sobre as ações destes. Uma forma subjetiva está em construção acelerada.

Então, de onde falam tais intelectuais? Como já foi afirmado anteriormente, tais docentes são membros de um corpo social que possui elevado status quo. São professores oriundos, em grande parte, de categorias profissionais altamente admiráveis e respeitáveis de Organizações Públicas, em especial do Judiciário e conexos, tais como: juízes de Direito e Federais, procuradores dos mais diversos ramos do Ministério Público da União e Estaduais, auditores-fiscais, renomados docentes universitários e autores ligados às Ciências Jurídicas, entre outros, de real significância dentro do espectro da Ciência Jurídica. 
A atuação desses membros e cientistas jurídicos, que estão conectados aos múltiplos Aparelhos de Estado, faz transparecer nesses "ambientes educacionais" vasta teia de relações de poder, as quais produzem simultaneamente resultados locais (no cursinho propriamente dito) e globais (nas demais conexões da vida desses estudantes). Uma conseqüência local desta relação poder/saber se exibe sobre as formas de se entender e sentir o estudo e outras formas de conhecer. O fundamento fornecido pelos princípios do desenvolvimento cognitivista tradicional não abre margem para invenção de outras formas de conhecer, de estudar e de aprender. Estas, em princípio, já estão dadas e estabelecidas de antemão, não permitindo interstícios ou fissuras para outras configurações de se estudar ou produzir um estudo diferenciado. Portanto, qualquer possibilidade de um aprendizado inventivo ou criativo tende a ser eliminado, rechaçado ou tornase invisível nestes "ambientes educacionais". Na verdade, há em curso inúmeros processos rizomáticos, sendo que, predominantemente, temos processo de erradicação dos modos inventivos.

Esses professores têm participação precípua na manutenção de verdades absolutas e conceitos estratificados, em especial no campo da educação, sobre os caminhos de um estudar produtivo e "vencedor". A atuação desses intelectuais, as formas verdadeiras de aprendizagem e o como estudar se conectam. Repensar o exercício do ensino e do papel desse intelectual é crucial.

\begin{abstract}
Parece-me que o que se deve levar em consideração no intelectual não é, portanto, "o portador de valores universais"; ele é alguém que ocupa uma posição específica, mas cuja especificidade está ligada às funções gerais do dispositivo de verdade em nossas sociedades. Em outras palavras, o intelectual tem uma tripla especificidade: a especificidade de sua posição de classe [...]; a especificidade de suas condições de vida e de trabalho, ligadas à sua condição de intelectual [...]; finalmente, a especificidade da política de verdade nas sociedades contemporâneas [...] há um combate "pela verdade", ou, ao menos, "em torno da verdade" - entende-se, mais uma vez, que por verdade não quero dizer "o conjunto das coisas verdadeiras a descobrir ou a fazer aceitar", mas "o conjunto das regras segundo as quais se distingue o verdadeiro do falso e se atribui ao verdadeiro efeitos específicos de poder" (FOUCAULT, 1979, p. 13, grifo nosso).
\end{abstract}

Há um acentuado, intensivo e estratificado posicionamento pelos professores de uma verdade perante os alunos, visto que estes os vêem como "o objetivo" a ser alcançado e almejado. Qualquer fala, atitude, comportamento, dica, "macete", "brincadeira" ou "piadinha" sobre o estudo e suas definições enrijecidas, enfim, qualquer gesto/atitude neste sentido produz efeitos práticos e políticos na fabricação de exemplos perfeitos e caminhos certos e seguros de alcançar a "vitória" da aprovação em concursos e esta, por sua vez, é naturalizada, serializada e produtora de instituições. 
Tais estratégias "vitoriosas e perfeitas" instauradas nestes espaços nos falam de determinados procedimentos institucionalizados que devem necessariamente ser seguidos e ritualizados. Por exemplo: possuir um número $x$ de horas de estudo diárias, mensais e anuais (p. ex.: duas mil horas de estudo/ano); prazos enrijecidos e generalizados para aprovação (p. ex.: um ano para todos os alunos); certos procedimentos comportamentais instituídos do ato de estudar (sentado, utilização do gênero atenção de maneira restritamente focalizada, fato que estimula o uso medicamentoso: ritalina); rituais organizacionais "comprovadamente científicos" (p. ex.: o método dos cinco "s"); locais saudáveis, higienizados, silenciosos, pacíficos (p. ex.: sem conflitos conjugais, religiosos, familiares, trabalhistas), "abstinências e renúncias imprescindíveis"10 (caso não realizadas, o fracasso é iminente e inevitável), modos de estar e ser estudantes disciplinarizados, bem regulados emocionalmente; regulação e controle da vida social e da saúde (onde posso ir, como, com quem, de que maneira, como devo me comportar, até que horas posso ficar, o que posso comer, o que devo evitar, que esporte/atividade física fazer, como fazê-los). Finalmente, certo esquadrinhamento capilar da vida se homogeneizou e, assim, maneiras de ser, de sentir, de perceber se instituíram nos poros da vida, fato que, concomitantemente, homogeneiza um rol de práticas cotidianas num processo de equalização das multiplicidades e singularidades. ${ }^{11}$

Estar fora desse modus operandi promove inúmeras fraturas, desassossegos, inquietações intrapsíquicas depreciativas nestes sujeitos, somando-se a isso a criação totalizadora e estereotipada de psicopatologias em alguns sujeitos. Como já afirmado no texto, tais procedimentos se institucionalizam, são subjetivados em modos de funcionamento; modos construídos no socius, mas vividos de forma intimista e privatista.

Por meio desta lógica da aprovação, determinada trajetória diferenciada sobre o estudar e/ou conduta destoante do exemplo estratificado e suas conexões praticadas por estes alunos é entendida, ou melhor, é sentida por estes como uma não-adaptação aos modelos perfeccionistas e idealizados engendrados sobre o como, quando, onde e de que forma estudar e aprender.

O que, então, está se produzindo nestes locais? Qual o resultado destes processos de subjetivação na vida desses alunos? Como tais espaços se acoplam aos processos de subjetivação fabricados pelo CMI? O que é ser empregável? Quais modos de educação estão sendo colocados em prática? Quais modelos psicopedagógicos estão sendo reproduzidos e fabricados nestes espaços? Como se produzem o acoplamento e a constituição do saber-poder produzido pelas Ciências Jurídicas e o saber-poder engendrado pelo sistema escolar tradicional? Por que e como tais práticas discursivas se mesclam a práticas não-discursivas?

\section{UM NOVO OLHAR SOBRE O ESTUDAR: É POSSÍVEL!}

Realizamos atividade específica na Clínica voltada para esses alunos, visto que o subscritor deste trabalho foi objetivado ${ }^{12}$ nesta experiência coletiva dos cursinhos, sendo esta, porém, vivenciada de forma singular e que se confluiu com certo projeto esquizoanalítico. O contato próximo e periódico com inúmeros 
alunos inseridos nesses espaços, bem como com alguns docentes ali presentes, possibilitou a criação concomitante de um provável campo de intervenção e de análise, e estes, paulatinamente, foram se co-engendrando com o espaço da clínica. Dessa forma, a construção de determinado trabalho intervencionista nos modos de produção e nos processos de institucionalização engendrados nesses ambientes foi se configurando e se confluindo a certo projeto cartográfico.
A cartografia participa e desencadeia um processo de desterritorialização no campo da ciência para inaugurar uma nova forma de produzir o conhecimento, um modo que envolve a criação, a arte, a implicação do autor, artista, pesquisador, cartógrafo. Seguindo este pensamento, marcado por um paradigma ético, estético e político, observa-se que, como um pesquisador/cartógrafo busca conhecer o seu pretenso objeto, este já está sendo inserido em novos processos que o transformam e o descaracterizam de sua forma original e isso se dando na duplicidade e no desdobramento da experiência que se vive do e no tempo de das formar que são esculpidas por este (MAIRESSE, 2003, p. 259).

Tal projeto produziu certo campo de pesquisa, ou melhor, um campo de análise com o qual, concomitantemente, o espaço da clínica foi-se acoplando a um campo de intervenção, fato que reforça sobremaneira qualquer indissociabilidade entre gênese teórica e social. O momento do trabalho clínico passa reciprocamente a ser o momento da produção teórica, de forma que este momento intervencionista fomenta determinados instantes de criação de outros processos de subjetivação. Temos, assim, neste espaço clínico, a elaboração cartográfica que nos objetiva a pensar as análises das implicações e as relações de poder em funcionamento nestes cursinhos. Nas palavras de Lourau:

A análise das implicações não é um privilégio; constitui, pelo contrário, uma dura coação, produzida pelo lugar que o intelectual ocupa na divisão do trabalho, da qual ele é um legitimador mais ou menos consciente. Estar implicado (realizar ou aceitar a análise das minhas implicações) é, ao fim e ao cabo, admitir que sou objetivado por aquilo que pretendo objetivar: fenômenos, acontecimentos, grupos, idéias, etc. (LOURAU, 2004, p. 148).

Completando o pensamento de Lourau, Coimbra traz:

A ferramenta "análise das implicações" supõe, dentre outras, as análises transferências daqueles que fazem parte da intervenção, a análise de todos os atravessamentos, ali presentes (sexo, idade, raça, posição sócio-econômica, crenças, formação profissional, dentre outras) e a análise das produções sócio-culturais, políticas e econômicas que 
atravessam esse mesmo estabelecimento e que também constituem os sujeitos que dele participam (COIMBRA; NASCIMENTO, 2004, p. 02).

A tal atividade clínica atribuiu-se intencionalmente certa "roupagem" caracterizada como certo "planejamento de estudo" que, no entanto, propõe a utilização conceitual - metodológica da Análise Institucional, à medida que esta nos auxilia neste processo de desinstitucionalização/desnaturalização dos módulos de funcionamento conectados aos modos de estudar enrijecidos e naturalizados por meio das atuais políticas de subjetivação. Em princípio, tal espaço tem como encomenda realizar, "no entender desses alunos", um adaptacionismo de suas vidas aos caminhos "corretos, universais e harmônicos" de um estudar/aprender perfeito e produtivo, ou seja, um aprendizado homogêneo, normatizado e institucionalizado. Certo fluxo unidirecional que permita uma acomodação/adaptação e que vá ao encontro dos pressupostos de um aprender cognitivista tradicionalista, isto é, que produza determinada superação real de deficiências cognitivas às quais estão sujeitos e que complete ou elimine as lacunas não preenchidas de um aprender já cristalizado e pronto para ser utilizado. A idéia de uma forma adulta, coerente e bem racionalizada do conhecer, segundo estes alunos, não está em vigência plena, eficaz e eficiente, ou sequer se exerce em suas vidas, bem como não está em sua forma maximizada, e por isso há uma elevada dificuldade no aprender e na adequação das "dicas e macetes" expelidos e reproduzidos pelos mestres e doutores. Como superar esta forma-subjetiva? Como promover diferentes formas de subjetividade?

Nestes "espaços educacionais", que funcionam no bojo das políticas de subjetivação capitalísticas, os modos de estudar encontram-se delimitados, esquadrinhados e com determinadas aplicabilidades instituídas e pré-formatadas. Os modos de estudar estão subjetivados nestes alunos e constituem, assim, o inconsciente político, determinando maneiras de agir, de pensar, de perceber, de entender, de querer, de "inventar" práticas e dispositivos de estudo modelados por trajetórias imbricadas em formatações enrijecidas.

Ao realizarmos esta atividade ("planejamento de estudo") no campo da Clínica, buscamos, a partir de alguns encontros realizados durante um mês e no espaço do consultório, colocar em funcionamento a afirmação de outras formas, outras perspectivas (paisagens) para se pensar o Estudar, almejando entendê-lo como uma forma potencializadora da vida, e não como um adoecer coletivo. Amplificar outros caminhos de se relacionar com o Estudo, extraí-lo do campo do sofrimento, da obrigação impreterível e necessária e, dessa forma, inseri-lo no campo do desejo ${ }^{13}$. Propor uma conceituação móvel da idéia habitual e subjetivada no socius que ronda, perpassa, margeia o Estudo, isto é, coloca-se em análise este conceito tradicionalista e subjetivado nas práticas educacionais do Estudar, suas maneiras, suas trajetórias, seus conceitos "coerentes", sua funcionalidade regulada por certa racionalidade cartesiana, objetivando, assim, movimentá-lo. Perturbá-lo para se deparar com outras paisagens e visualizá-lo como uma duna: sempre móvel e imprevisível ${ }^{14}$. Para tanto, o conceito negativo estratificado e 
entrincheirado na forma-sujeito contemporânea sobre o Estudar, seu modelo instituído e suas formas institucionalizadas, deve ser traumatizado, esfacelado e transversalizado pela ação de outras forças e outras instâncias (a organização, o grupo, o indivíduo e as relações). Em outras palavras, repotencializar o Estudar de forma que possa trazê-lo para o campo da paixão e da alegria, buscando, para isso, fomentar a criação de processos de transformação que produzam um conhecer sobre a realidade estratificada e hierarquizada.

Dessa forma, o espaço da Clínica propõe-se afirmar a produção de olhares diferenciados ou de perspectivas inovadoras. Uma reconfiguração dos modelos tecnicistas instituídos pelos espaços educacionais citados, bem como uma aposta em processos do Estudar que colocam em questão regras, valores, condutas e comportamentos, leis de verdades estabelecidos a priori e que produzam, ao mesmo tempo, estratégias singularizadas para o enfrentamento cotidiano, táticas que produzam um estudo positivado e menos culpabilizador. Neste "planejamento de estudo" procura-se elaborar determinada processualidade que promova a instauração de processos de ruptura com as instituições ${ }^{15}$ que circulam pelo socius, fato que nos faz pensar a constituição de certas relações de poder constituidora de sujeição, de subjetivação e de submissão. Na Clínica:

O caráter híbrido das estratégias de intervenção está exatamente no ponto onde a solução de problemas convoca seu rearranjo, a invenção de um novo território onde tal problema será necessariamente outro. A solução de um problema se confunde com a criação de um outro problema. É por isso que podemos dizer que na clínica importa muito mais a criação de novas entradas do que a "descoberta" de saídas (PASSOS; BARROS, 2003, p. 85).

O planejamento possibilita a construção e a afirmação das experiências que perpassam estes alunos, ou seja, almeja potencializar as expressões ali produzidas, evitando, dessa forma, a busca da certa representação da realidade naturalizada das experiências coletivas na condução da criação. Para tanto, a verdade dos caminhos "vitoriosos" é repensada, o absoluto é recodificado, uma recodificação que coloque em funcionamento outras linhas de fuga, menos tiranas, menos absolutistas, menos adoecedoras da vida desses alunos e professores, em resumo, menos fascistas. Portanto, na clínica, não objetivamos o enrijecimento de outros modos, fato que nos levaria fatalmente a uma inversão do método atual, e, sim, a problematização e a desinstitucionalização de certos modos de funcionamento em vigência e, a partir daí, propor a invenção de outras conexões. Perpassamos, logicamente, por diversos questionamentos das atuais políticas de subjetivação engendradas pelo CMI, dado que estes cursinhos não são modos autônomos na produção de subjetividade, mas, sim, encontram-se acoplados aos modos de subjetivação contemporâneos. 


\section{Mudanças?}

Quais caminhos para repensar este funcionamento destrutivo da vida? Que possibilidades para avaliar esta forma de produção de nada de vontade? Dentro dessa paisagem educacional altamente despotencializadora e geradora de adoecimento nefasto e coletivizador, quais fluxos ou alternativas poderíamos propor para se pensar o Estudar desenvolvido neste espaço da Clínica dentro desses ambientes educacionais? Quais inventividades não condicionantes do Estudar poderíamos (re)pensar para uma atuação potencializadora da vida nestes ambientes educacionais? Uma tarefa árdua, no entanto possível, à proporção que possamos inserir um reposicionamento, um questionar cotidiano e potencializador sobre o conjunto de pressupostos, de preceitos, de preconceitos e de tendências que estruturam o Estudar e o Aprender e, dessa forma, oferecer uma chance ou criar fissuras para que as infinitas e plurais possibilidades de fuga possam ter acesso ao novo, às formas menos tiranas de racionalização metódica e perfeita, as quais estão engessadas por esta forma-subjetiva em continuação/produção no cotidiano contemporâneo sobre o aprender e, sobretudo, sobre o Estudar. Devemos pensar que:

[...] aprender não é reproduzir, mas inaugurar; inventar o ainda não existente, e não se contentar em repetir um saber: "fala-se - percorro outra vez o mesmo texto - fundo daquilo que não se sabe, de seu próprio sentido, de seu próprio desenvolvimento, deu um conjunto de singularidades soltas"; pois é preciso desfazer os "aparelhos de saber", as organizações preexistentes, incluídas as do corpo, para devir, entrar em devires que comandam e balizam toda criação [...] não se pode aprender sem começar a se desprender. A se desprender, é claro, dos preconceitos anteriores, mas antes de tudo, e sempre, a se desprender de si (SHERER, 2005, p. 02).

Permitir um Estudar criativo, inventivo, satisfatório e, principalmente, heterogêneo é pensar nas multiplicidades e similitudes que possibilitam a construção ou o engendramento de condições de possibilidades de estudos favoráveis e potencializadores. Reduzem-se as possibilidades de se articular formas inventivas de estudo sem levar em consideração os agenciamentos ${ }^{16} \mathrm{e}$, em especial, os infinitos encontros constantemente presentes nestes espaços educacionais. Falar em agenciamentos é se permitir pensar nas multiplicidades e similitudes que possibilitam a construção e/ou engendramento de condições de estudos favoráveis e potencializadoras para que, dessa formar, faça-se possível criar outros sentidos, outras formas de dizer e experimentar o Estudar, bem como engendrá-lo por outros viés e modalidades singularizantes, por outras significações a serem desenvolvidas, enfim, instituir uma concessão a outros modos de existência. Podemos pensar o agenciamento como um "crescimento das dimensões numa multiplicidade que muda necessariamente de natureza à medida que ela aumenta suas conexões" (DELEUZE, 1995, p. 17). 
Os agenciamentos produzem inúmeras conexões, as quais, por sua vez, assumem certos modos de funcionamento rizomático à medida que não hierarquizam tais relações ou instituem rigidez subordinativa entre elas. Nestes sistemas de rizoma, as partes podem se conectar sem que, para isso, tenham que seguir caminhos predeterminados e pré-formatados. Tal fato faz emergir inúmeras linhas de fuga, as quais podem produzir bons encontros ou não, criar outros territórios existenciais ou não. Isto significa que esses agenciamentos podem também produzir linhas de fugas que não estejam necessariamente comprometidas com a vida ou com a criação de formas mais potencializadoras, mas, sim, fabricar segmentaridades, situações conflituosas, angustiantes e despotencializadoras do viver. Sendo assim, falar em agenciamento não é afirmar unidimensionalmente seu caráter criador e inventivo, mas afirmar de modo recíproco os possíveis e os infinitos fluxos desestabilizadores, bem como a produção de linhas de segmentaridades.

Dentro desta perspectiva, um passo pioneiro que se faz inadiável e impreterível é repensar esta relação cristalizada entre alunos e professores. Uma abstração real, uma desconstrução do status quo atrelada à imagem dos professores como da atividade docente, a qual funciona como princípio de conhecimento necessário, irremediável e produtor de verdades, enfim, afirmar a desconstrução de trajetórias de vontade de verdade que se institucionalizam em exercícios de saberes. Promover efetiva desarticulação de certas tecnologias de poder ${ }^{17}$ que produzem freneticamente formas incondicionais a respeito do verdadeiro e, dessa forma, agenciar processos de desconstituição das formas de saber-poder que se exercem não apenas pela repressão ou por formas ideológicas das ciências jurídicas, mas por dispositivos de poder constitutivos de regimes de verdade (como, quando e de que forma estudar), os quais desenvolvem estratégias vitoriosas e perfeitas, uma espécie de ratificação constante da verdade e seus pressupostos de existência. Um "desarmamento" político dos gestos, das falas, das "histórias vitoriosas", dos caminhos pré-estabelecidos, das formas concretas e reais de aprendizagem. Em resumo, provocar impetuosamente uma desconexão e uma não-hierarquização às verdades e, com isso, reinventar possíveis (re)conexões aos infinitos agenciamentos e com emergentes e iminentes linhas de fuga, assim como dos modos inventivos de se pensar o Estudar e suas formas pluralísticas de atuação e exercício.

Este modelo atual em funcionamento dentro desses espaços educacionais, a formação, criação e desenvolvimento de conceitos individualistas do "fracasso", é fortalecido e corporificado de forma espantosa e formidável. Ou seja, tal "fracasso" engendra-se intrinsecamente nas formas da visibilidade e dizibilidade $^{18}$. O dantesco atrelamento entre desistências, fatigamentos, fatos intempestivos, diversidades de problemas emergentes do cotidiano contemporâneo e vontade individual é amplificado e reforçado, criando-se, de tal modo, um conceito em formação de que pessoas inseridas nestes locais estão sendo conectadas à idéia de incapacidade e fraqueza intelectual. Em outras palavras, são inabilitados e incapazes de gerir e suportar a ampla carga de disciplinas e o acúmulo de conhecimento propagado nestes espaços. Com isso, uma vultosa culpabilização 
floresce e se propaga nos "corações e mentes", culpabilização essa que reforça idéias de fracassos individualistas, intimistas e responsabilidades não coletivas. A máxima: "minha culpa, minha culpa, minha máxima culpa" tem um amplo campo para disseminação.

Sendo assim, visualizamos a produção/reconstrução de outras expressões que, por sua vez, afirmem outras realidades e, por meio destas, a criação de processos de desinstitucionalização de falas e dizeres que produzam formas-sujeitos menos inflexíveis, bem como menos instáveis e impermeáveis à ampla margem de formas e forças heterogêneas que os constituem.

O que queremos afirmar é a possibilidade de se articular formas inventivas de estudo, e aqui não estamos falando apenas de formas de invenções particularizantes do aluno inventor de estratégias e técnicas comportamentais, caso se leve em consideração os infinitos agenciamentos que, em sua multiplicidade, fazem funcionar simultaneamente fluxos semióticos, materiais e sociais. Em especial, permitir a existência prática de funcionamento dos diversos modos vida e dos encontros constantemente presentes nestes espaços educacionais. Caminhar no sentido de permitir o Estudar como processo de produção de subjetividade e da subjetividade como invenção de si, um arquitetar, um invento do próprio mundo. Ao realizarmos tal trajetória, talvez possamos extinguir, ou ao menos perturbar, esta idéia nefasta sobre o "fracasso" conectado à vida destes alunos, causando a estes corpos certa ruptura com este adoecimento exacerbado e latente, visto que este é produzido mesmo quando tais alunos "descobrem" o não interesse por esta nova configuração da empregabilidade contemporânea.

Ao propormos certa ruptura com este estereótipo do aluno fracassado, talvez a lamentação, a tristeza, as paixões tristes, o fatigamento e a indignação perpassadas por estes alunos possam ser dissipadas, diluídas, concomitantemente à produção de novos territórios existenciais. Assim, visualizar o florescer de vidas mais alegres, mais vivas, mais potencializadas e produtivas para si mesmos. Deixar as tantas linhas de ruptura seguirem percursos fortalecedores e inventivos ou não. Se pensarmos numa construção de um Estudar que seja um intercessor, que produza um efeito desestabilizador, que produza ação inventiva e até mesmo criativa, poderemos vislumbrar o surgimento de pessoas mais ativas, mais apaixonadas pela criação de saberes intensivos e provocadores de metamorfoses. O que fazer então? Vamos dar uma chance a estes alunos e mostrar-lhes que "o lamento e a indignação não produzem transformação" (MACHADO, 1999, p. 227), somente a destroem. 


\section{Notas}

1 O CMI não se manifesta somente pela exploração do trabalhador, mas também pela exploração da vida (sexualidade, relacionamentos amorosos e familiares entre outros).

2 "Desterritorialização é um movimento de destruição dos territórios constituídos, podendo desdobrar-se em processos de territorialização, onde novos territórios provisórios seriam inventados. Ou em processos de reterritorialização, onde o processo de recomposição de territórios vinculados à ordem de produção capitalística. Os territórios e as desterritorializações fazem parte e produzem formas de subjetividade" (MACHADO, 1999, p. 217). Dentro das idéias de Deleuze, podemos pensar territorialização e desterritorialização como processos que se desenvolvem simultaneamente. Em uma trajetória posterior, a reterritorilização insere a possibilidade de reposicionamento de um determinado território encravado num processo de desterritorizlização (GUATTARI; ROLNIK, 1986-2000).

3 Podemos entender "Linhas de fuga" como um pensar que não se enclausura sobre saberes e entendimentos enrijecidos, e sim coloca em ponto de discussão formas estabelecidas ou paradigmas sociais e, assim, se engajam na produção de outros agenciamentos, outras relações. É exatamente sobre os conhecimentos dados que se criam discordâncias (linhas de fuga) que exercem a tensão de ruptura nas relações que se processam. Em resumo, podemos dizer que Linhas de fuga rejeitam serializações e visam escapar, fugir de normas instituídas / epistemes.

4 Estes espaços demonstraram um elevado crescimento nos últimos dez anos, uma proliferação significativa e que não pode ser simplesmente marginalizada ou entendida como metamorfoses naturais e verdadeiras do mundo contemporâneo reguladas pelo CMI. No Município de Vitória - ES, este crescimento foi da ordem, aproximadamente, de quinhentos por cento nos últimos dez anos. No ano de 1997, havia dois espaços, localizados e restritos; hoje, o número passa de seis cursos. Contudo, o mais importante é o aumento no número de filiais desses cursos em todo o Estado do Espírito Santo. Soma-se a isto a entrada neste nicho mercadológico dos "antigos" cursos pré-vestibulares, engrossando, assim, a quantidade de cursos oferecidos. No entanto, estes dados "não são totalmente confiáveis", visto que "não há pesquisas sobre a expansão desses locais", fato que torna difícil qualquer mensuração exata. Os únicos dados existentes são a quantidade de anúncios televisivos, jornalísticos e toda a indústria que se arquitetou. Desde o aumento numérico de estabelecimentos aos "manuais de auto-ajuda" que recheiam as livrarias. Diante desse quadro, a quantidade de pessoas que passam por estes espaços mostra-se significante. É bom lembrarmos que toda forma de saber produz relações de poder, as quais, por sua vez, produzem novas formas de saberes. Diante disso, nesta nova configuração educacional, novos especialismos e especialistas fazem transparecer regimes de verdades, os quais, simultaneamente, produzem outras relações de poder. Enfim, temos saberes que circulam e que fazem funcionar outras relações de poder.

5 Comparação aqui entendida dentro da polarização Bom e Mal.

${ }^{6}$ Serializada: o que é idêntico, igual e/ou homogêneo, algo que é fabricado em série, algo que se reproduz como um modelo.

7 O exercício do poder "é um conjunto de ações sobre ações possíveis; ele opera sobre o campo de possibilidade onde se inscreve o comportamento dos sujeitos ativos; ele incita, induz, desvia, facilita ou torna mais difícil, amplia ou limita, torna mais ou menos provável. No limite, ele coage ou impede absolutamente, mas é sempre uma maneira de agir sobre um ou vários sujeitos ativos, e o quanto eles agem ou são suscetíveis de agir (FOULCAULT, 1995, p. 243).

8 "Uma relação de poder é um modo de ação que não age direta e imediatamente sobre os outros, mas que age sobre sua própria ação. [...] se articula sobre dois elementos que lhe são indispensáveis por ser exatamente uma relação de poder : que "o outro" (aquele sobre o qual ela se exerce) seja inteiramente reconhecido e mantido até o fim como o sujeito de ação; e que se abra, diante das relações de poder, todo um campo de repostas, reações, efeitos, invenções possíveis" (FOUCAULT, 1995, p. 243). É significante lembrarmos que o exercício do poder, a ação sobre a ação do outros, mostra-se ligado certo elemento fundamental: a liberdade. Esta é necessária para práticas de exercício do poder.

9 Os docentes que lecionam nestes locais são majoritariamente oriundos de categorias profissionais vinculadas à Administração Pública, em especial do Judiciário e conexos tais como: procuradores do Ministério Público da União e Estaduais, auditores-fiscais, renomados docentes universitários, autores ligado às Ciências Jurídicas, entre outros ligados a tais Ciências. "Sendo assim, os alunos visualizam este status quo, e não a carreira de professor propriamente dito". O "objetivo" é o status quo. 
${ }^{10} \mathrm{~A}$ idéia de produtividade está íntima e profundamente ligada à questão da quantidade determinada de horas despendidas, "sacrificadas", "abdicadas" e "renunciadas" na prática do estudar cotidiano. Traço forte ou característico da sociedade disciplinar, considerando o aumento de determinada força produtiva (horas de estudo) com a simultânea diminuição de força política.

${ }^{11}$ Esta nota se faz necessária, visto que, neste parágrafo, tendemos a ponderar certa similitude com os Cursinhos Pré-Vestibulares. Nestes espaços a questão da empregabilidade não assume um fator primordial para a sustentabilidade da vida. No entanto, nos cursinhos para concursos públicos, um elevado número de alunos já passou por processo de graduação, sendo assim, a questão de se tornar empregável assume contornos diferenciados e mais rigorosos, à medida que há certa urgência em se tornar empregável. Tais pessoas objetivam a passagem por tais estabelecimentos como uma das poucas oportunidades de empregabilidade (salários razoáveis e estabilidade eterna).

${ }^{12}$ Tal experiência coletiva já demonstra qualquer pretensão de objetividade e neutralidade tão bem racionalizadas pelo paradigma positivista. Isto demonstra, inicialmente, as bases do conceito de implicação proposto por Lourau. Isto é, este "estar implicado" escapa dos sinônimos de teologal, de pessoalidade, de comprometimento personalíssimo, afetivo ou motivacional. "A implicação não é uma questão de vontade, de decisão consciente. Ela inclui uma análise do sistema de lugares, o assinalamento do lugar que ocupa, que busca ocupar e do que lhe é designado a ocupar com os riscos que isto implica (BARROS, R., 2007, p. 231).

${ }^{13}$ Desejo não atrelado à falta, renunciando ao par sujeito - objeto (aquele que deseja e aquilo que é desejado). No caso em tela, o aluno que deseja estudar e, assim, a prática do estudar é sempre o objeto do desejo. Contrariamente, pensamos em um desejo que produz territórios, à medida que engendra uma infinitude de agenciamentos e de relações, ou seja, criar e elaborar principalmente novos regimes de signos.

${ }^{14}$ Quanto afirmamos esta imprevisibilidade, não nos referimos ao caos absoluto e/ou ausência de técnicas de organização, e sim ao fortalecimento de um imprevisível que possa afirmar outros modos e outras maneiras de pensar, de agir perante o desassossego da meta-estabilidade proposta pela metodologia subjetivada de um estudo saudável (zoé e bios), produtivo e bem racionalizado. Um imprevisível que possa potencializar atitudes.

${ }^{15}$ É fundamental dizer que o termo "instituição" aqui utilizado não é sinônimo de estabelecimento, de organização ou de uma Lei, nem é um sentido Jurídico-Estatal. Utilizamos esse termo para nos referirmos às regras, às leis, às políticas, à história, aos costumes, aos movimentos sociais, bem como aos desejos, aos projetos de vida, os quais atravessam os inúmeros estabelecimentos e os modos de subjetivação. Nas palavras de Lourau: "Hoje em dia já não é possível conceber as instituições como um estrato, uma instância ou um nível de uma formação social determinada. Pelo contrário é necessário definir instituição como um cruzamento de instâncias (econômicas, políticas, ideológicas e desejantes) e afirmar além do mais, empregando a linguagem da análise institucional: se é certo que toda instituição é atravessada por todos os níveis de uma formação social, a instituição deve ser definida necessariamente pela transversalidade". (LOURAU, 2004, p. 76)

${ }^{16}$ Por agenciamento podemos entender que Guattari e Rolnik se referem a uma noção mais ampla do que a de estrutura, sistema, forma. Um agenciamento comporta elementos heterogêneos, tanto da ordem biológica quando social maquínicas. (GUATTARI; ROLNIK, 1986-2000, p. 317).

${ }^{17}$ Podemos entender como tecnologias de poder as manutenções de privilégios, as autoridades estatutárias institucionalizadas, as práticas profissionais hierarquizadas, os pilares de hierarquização organizacional e jurisdicional cuidadosamente elaboradas nos dispositivos estatais e que se propagam simultaneamente nestes espaços educacionais etc.

18 "Da gênese empírica das formas de visibilidade criam-se modos de ver e fazer ver; já da produção das formas de dizibilidade surgem maneiras específicas de falar, regimes de discursos ou de signos, como preferem Deleuze e Guattari. [...] São dois planos de realizações que, embora distintos, não se isentam de intervenções mútuas. Dito de outro modo, as formas do visível e do dizível, agindo em regime de reciprocidade, constroem nosso saber sobre a realidade, respectivamente, os objetos visíveis e os temas a serem tratados nos discursos. A linguagem, portanto, articulada às práticas mudas junto aos corpos instaura realidades" (TEDESCO, 2003, p. 02). 


\section{REFERÊNCIAS}

BARROS, R. B. Grupo: a afirmação de um simulacro. 1. ed. Porto Alegre: Sulina; UFRGS, 2007.

COIMBRA, C.; NASCIMENTO, M.L.Sobreimplicação: práticas de esvaziamento político? Niterói: Universidade Federal Fluminense, 2004. Disponível em: http:// www.slab.uff.br/exibetexto2.php?link=.\%2Ftextos $\% 2$ Ftexto 22. htm\&codtexto $=2$ $2 \& \operatorname{cod}=22 \&$ tp $=$ t\&nome_autor=>. Acesso em: 30 set. 2007.

DELEUZE, G. Mil Platôs: capitalismo e esquizofrenia. Rio de Janeiro: Ed. 34, 1995. v. 1.

DROIT, R.-P. Michel Foucault: entrevistas. Rio de Janeiro: Graal, 2006.

FOUCAULT, M. Microfísica do poder. Rio de Janeiro: Graal, 1979.

. Em defesa da sociedade: curso no Collège de France (1975-1976). São Paulo: Martins Fontes, 2005.

. O sujeito e o poder. In: DREYFUS, H.; RABINOW, P. Michel Foucault: uma trajetória filosófica. Rio de Janeiro: Forense, 1995.

GUATTARI, F.; ROLNIK, S. Cartografias do desejo (1986). 6. ed. Petrópolis : Vozes, 2000.

HAESBAERT. R; BRUCE; G. A. A Desterritorialização na Obra de Deleuze e Guattari. GEOgraphia. Niterói, ano IV, n. 07, p. 03-11, 2002. Disponível em: $<$ http://www.uff.br/geographia/rev_07/rogerio7.pdf>. Acesso em: 09 out. 2006.

KASTRUP, V. Políticas cognitivas na formação do professor e o problema do devir-mestre. Educação \& Sociedade, Campinas, v. 26, n. 93, 2005. Disponível em: $<$ http://www.scielo.br/scielo.php?script=sci_arttext\&pid=S0101-733020050 00400010\&lng=pt\&nrm=iso $>$. Acesso em: 09 out. 2006.

LOURAU, R. Uma apresentação da análise institucional. In: ALTOÉ, S. (Org.). Analista institucional em tempo integral. 1. ed. São Paulo: HUCITEC, 2004. v. 1, p.76-148.

MACHADO, L. D. Subjetividades Contemporâneas. In: BARROS, M. E. B. (Org.). Psicologia: questões contemporâneas. 1. ed. Vitória, ES: EDUFES, 1999. v. 1. p. 211-231. 
MAIRESSE. D. Cartografia: do método à arte de fazer pesquisa. In: FONSECA, T. M. G.; KIRST, P. G. (Org.). Cartografias e devires: a construção do presente. Porto Alegre: UFRGS, 2003. p. 259-272.

PASSOS, E. Os dispositivos clínico-políticos e as redes no contemporâneo. Entrelinhas do Conselho Regional de Psicologia CRP-07, Porto Alegre, p. 8-9, 2000 .

PASSOS. E, BARROS, R. B. Complexidade, transdisciplinaridade e produção de subjetividade. In: FONSECA. T. M. G.; KIRST, P. G. (Org.). Cartografias e devires: a construção do presente. Porto Alegre: UFRGS, 2003. v. 1, p. 81-89.

PELBART, P. P. A vertigem por um fio: políticas da subjetividade contemporânea. São Paulo: Iluminuras, 2000.

PRATA, M. S. A produção da subjetividade e as relações de poder na escola: uma reflexão sobre a sociedade disciplinar na configuração social da atualidade. Revista Brasileira de Educação, Rio de Janeiro, n. 28, 2005. Disponível em: $<$ http:/www.scielo.br/scielo.php?script=sci_arttext\&pid=S1413-247820050001 00009\&lng=pt\&nrm=iso $>$. Acesso em: 09 out. 2006.

SCHÉRER, R.. Aprender com Deleuze. Educação \& Sociedade, Campinas, v. 26, n. 93, 2005. Disponível em: <http:/www.scielo.br/scielo.php?script=sci arttext\&pid $=\mathrm{S} 0101-73302005000400003 \& \operatorname{lng}=\mathrm{pt} \& \mathrm{nrm}=\mathrm{iso}>$. Acesso em: $0 \overline{9}$ out. 2006.

TEDESCO, S. A natureza coletiva do elo linguagem-subjetividade. Psicologia: Teoria e Pesquisa, Brasília, v. 19, n. 1, 2003. Disponível em: $<$ http://www.scielo. br/scielo.php?script $=$ sci_arttext\&pid $=$ S0102-37722003000100011\&lng=en\&nr $\mathrm{m}=\mathrm{iso}>$. Acesso em: 06 out. 2006.

. A linguagem como dispositivo de subjetivação no contemporâneo. $\overline{\text { Palestra }}$ apresentada em Porto Alegre, no II Colóquio Interdepartamental subjetividade, Clínica e Política (UFF/ UFRJ/PUC - SP/UFRGS/ Paris 8, p. 02, dez. 2002.

Recebido em: março de 2007

Aceito em: novembro de 2007 